\title{
MITOS DE GERAÇÃO E SUCESSÃO EM HESÍODO: URANO, CRONOS E ZEUS
}

\author{
OLIMAR FLORES JÚNIOR \\ Universidade Federal de Minas Gerais
}

\begin{abstract}
Resumo: A Teogonia de Hesiodo é um relato mítico que descreve o movimento do universo, desde o princlpio, até uma ordem final, hierarquizada segundo poténcias divinas, e como este movimento se revela aos homens através da força presentificadora das Musas. Este trabalho visa exatamente delinear, sob o ponto de vista do poder, as geraçóes e as sucessóes embutidas no mito, a partir do Céu, e também interpretar o que representa cada instáncia do poder, como se instaura e como se comporta no exercício da ordem dentro do processo de evoluçăo do mundo.
\end{abstract}

Palavras-chaves: Heslodo; mitologia grega;teogonia; cosmogonia.

Na Teogonia de tieslodo, os primeiros versos que seguem o proêmio às musas, descrevendo a genealogia dos deuses primordiais, relatam uma ordem de sucessão fundamental do kósmos: a passagem do nada à existência do mundo. Caos, Terra e Eros são o princípio natural, a arkhé do mundo, dos deuses e dos homens.

A partir deste ponto a (con)formação do universo tende a tornar-se cada vez mais complexa, a sucessão de deidades (con)funde-se com uma sucessão de procedimentos, os nascimentos por cissiparidade com aqueles oriundos de uniōes amorosas, tudo permeando mudanças de poder e de sua natureza, até a sua constituição o final com Zeus.

Temos na cosmogonia hesiódica, marcadas, duas linhagens principais: uma derivada do Caos, outra da Terra, sendo que a terceira entidade da trilogia fundamental, Eros, atua, em ambas indistintamente, como o princlpio que possibilita as gerações, o movimento do uno em direção ao múltiplo. Destas duas linhagens, a da Terra interessa mais de perto, pois está vinculada a todos os momentos do poder dentro do plano mítico, inclusive à emergéncia maior, Zeus. Desta perspectiva, a descendéncia de Caos se impōe na condição de alteridade em relação aos filhos da Terra; de fato, enquanto com a Terra estão relacionados os deuses venturosos doadores-de-bens, os ollmpicos, que lutam pelo poder e o exercitam em suas formas diversas, segundo os desígnos de Zeus, do Caos emergem, como observa Torrano (1981), sobretudo as forças negadoras do ser, aquelas que invocam obscuridade e maleflcios (1); a Noite, com seus filhos - hediondo Lote, Sorte negra, Morte, Sono, Escárnio e Miséria - descendem do Caos.

Quanto ao poder, se podemos entendé-lo também como designação de atribuiçōes, a própria Terra é quem primeiro o exerce:

"Terra primeiro pariu igual a si mesma

Céu constelado, para cobri-la toda ao redor

e ser aos deuses venturosos sede irresvalável sempre" (vv 126-28)

1. Exceto Éter e Dia. Observam bem a esse respelto Ana Lúcia S. Cerqueira e Marla Therezinha A. Lyra (1979:29): "Na Teogonia a materia opaca e intorme aparece primelramente a o mundo se desenvolve ciclicamente passando das trevas a luz. Entendida desta manelra náo parecerá estranho que a Noite tenha gerado Éter e Dla." 
Por uma "expansão partenogênica", como define Annie Bonnafé (1985:25), Urano, o Ceú constelado, surge já com uma atribuiçāo especffica delegada pela Terra: cobri-la toda ao redor (esta primeira atribuição pode, sem dúvida, ser tomada em duplo sentido: um geo-físico, como conhecemos; outro amoroso, sexual, a própria cópula que resulta numa nova geração: os Titãs, os Ciclopes e os Hecatônquiros) e ser aos deuses venturosos morada segura. A possibilidade de gerar e precisar a finalidade e, por assim dizer, o limite do ser gerado traduz um modelo de poder que, neste momento, a Terra incorpora. Além disso, o Céu aparece, sob certo aspecto, paritário com relação à Terra, pois igual a ela própria é relatado. Ambos constituem édos asphalès aiel, "sede irresvalável sempre", porém no Céu se assentam não todos, como na Terra, mas apenas os deuses venturosos. O estatuto do Céu, ampliado para a função paterna, é assim definido pela Terra que, curiosamente, exercendo o poder, transfere-o ao próprio Céu. Podemos considerar que, no fio condutor da narrativa mítica, este é o único momento em que a sucessāo no poder se dá não por embate direto entre forças antagônicas, uma de conservação e outra de renovação, mas por uma espécie de concessão da entidade a ser substitulda no exercicio da ordem.

Nota-se também que o fim da dinastia do Céu acontece quando se verifica uma desmedida no seu comportamento, a hybris (2) que, paradoxalm€nte, o coloca em choque com quem antes o havia instituido no poder: a Terra. Esta hybris é a própria negação da luz aos filhos:

"Quantos da Terra e do Céu nasceram

filhos os mais terriveis, detestava-os o pai

dês o começo: tão logo cada um deles nascia

a todos ocultava, à luz não os permitindo,

na cova da Terra." ( $\mathrm{v}$ 154-58)

De Urano, o Céu constelado, devia emergir a nova geraçāo, mas da luz ele a oculta; é o momento de nova substituição no poder para que, segundo os desígnios de Zeus, o plano mitico venha a ser.

Outra vez a Terra preside a origem desta sucessão:

"Alegrava-se na maligna obra

o Céu. Por dentro gemia a Terra prodigiosa

atulhada, e urdiu dolosa e maligna arte" (vv 158-60).

A concepção do plano amplia-se na prática:

"Rápida criou o gênero do grisalho aço

forjou grande podão e indicou aos filhos.

Disse com ousadia, ofendida no coração,

'Filhos meus e do pai estólito, se quiserdes

ter-me fé, puniremos o maligno ultraje de vosso

pai, pois ele tramou antes obras indignas.' " (vv 161-66)

cerne da indignidade das obras do Céu está, com certeza, na desmedida do cumprimento de sua atribuição, ou seja, do exercĺcio do poder.

2. O uso do conceito de hybris, mais próprio no vocabulário homérico, pode ser estendido a Hesíodo. A insolencia ou o ardor excessivo dos pretendentes no palácio de Ulisses, Od. 1,$368 ; 4,321 ; 4,627$; etc. entendido como um ultraje a leis divinas (porque divina era a honra de um rei), traduz-se, na Teogonia, nåo como falta humana, mas como desmedida de um deus diante de uma ordem superior representada por outro deus. 
A Urano sucede Cronos, que traz na origem de seu governo já um dado importante: o livre-arbítrio. Ele não é designado, decide o próprio destino quando acata as exortações da mãe enquanto, aos seus outros irmãos, "a todos reteve o terror" (vv 167). Ao apresentar a arma aos filhos nem a Terra, nem nada de antemão sugere que a honra da sucessão caberá a Cronos; existe apenas um destino, um desígnio a ser cumprido, do qual ainda năo se conhece o sujeito. O impasse, que nesse momento acontece, amplia a força da escolha e amplia também a força com que Cronos emerge. Em outras palavras, essa possibilidade de escolha entre o cumprimento ou não do destino do kósmos, que entāo é evidente, ressalta a singularidade e a excelência, a areté ${ }^{3}$ de Cronos frente à pluralidade obscurecedora dos demais Uranidas. Além disso, o acerto de sua decisão envolve tanto a força que sustenta a coragem, quanto o bemdiscemir provido pela astúcia, a ankylométis, virtude também identificada com Cronos. Assim, a decisão ergue-se sobre a força que garante o sucesso da empreitada e sobre a ankylométis, que bem a orienta, fazendo Cronos confiante nas palavras e tramas da mãe Terra. Na realidade, ainda que de forma mais fraca e pouco articulada (pois não apresenta propriamente uma iniciativa, ou seja, uma concepção de procedimentos adequados e sim apenas o posicionar-se diante de uma situação apresentada), Cronos já conjuga aquilo que em Zeus será maior e meIhor definido: a harmonia entre o saber/conhecer astucioso e a potência da ação. A diferença da astúcia de Cronos reside exatamente no fato de que ela é retorcida: ankylo-métes, métis angulosa ou curva. Como se obedecesse a uma seqüência lógica, o poder passa de Urano, que não possui esta inteligência/sabedoria/astúcia, a Cronos, que a possui um tanto deformada, até atingir a plenitude com Zeus, ao desposar e logo devorar Métis, a Astúcia, filha de Tétis e do Oceano.

Cumpre a Cronos, então, proceder ao último ato da tomada do poder: a ritualística castração de Urano. Esse embate, em que, orientado pela Terra e valendo-se da foice forjada por ela, decepa e lança ao mar os órgãos genitais do pai, faz ressurgir a idéia da hýbris de Urano. O golpe é desferido justamente no ponto capital através do qual o Céu executa suas atribuiçōes e pelo qual também transgride ultrapassando-as. No entanto, nāo há coincidência nem gratuidade: a castração é o ato de refrear a fertilidade desmedida e, de certa forma, improdutiva (já que a prole não chegava à luz) de Urano; refreia, assim, duas forças paradoxais: por um lado, esse apetite desmesurado e, por outro, a negação dos filhos. De fato, como declara Vernant (1988:65), esta ação tem conseqüências cósmicas decisivas. Urano ainda será a sede irresvalável dos deuses venturosos, mas perde a capacidade de continuar gerando, é alijado do poder e, sobretudo pela grande obra de Cronos, o mito tem seu curso garantido, pois a Terra pode então dar à luz os seus outros filhos titånicos.

Por outro lado, a própria castração de Urano ainda foi capaz de gerar, pois:

"Nada inerte escapou da mão" (v 182).

Nascem as Erínies, os Gigantes, as ninfas freixos e Afrodite. São deidades limftrofes, pois emergem no limiar entre um momento do poder e outro; e, mais do que o instante em que são geradas, a sua própria natureza reforça esta situação fronteiriça: são estas divindades filhas de Urano ou de Cronos? Se, de um lado, a matéria de onde brotam pertence a Urano, por outro, a ação que possibilita o nascimento é executada por Cronos.

3. "Desde que um indivfduo se empenha numa opçáo, que se decide, qualquer que seja o plano em que se situe sua resoluçăo, ele se constitui a si próprio como agente". Assim Vernant (1988:42) enquadrou o livre-arbftrio do sujeito trágico. O livre-arbftrio dos deuses, aqui de Cronos, circunscreve-se no plano da coragem, qualidade intrínseca ao campo semântico de areté, que em Homero, correspondendo a uma aptidáo ffsica, 11. 20,411, ainda significa um instrumento para a açáa. A possibilidade da escolha parece ser sempre pano de fundo dos momentos em que a areté se manifesta, dal seu uso na descriçăo do papel de Cronos. Na tragédla, em um dado momento, a multiplicidade das opçoes reduzem-se, por uma intervençăo divina, a uma única, sobre a qual dever recair a escolha do herol; nesse sentido (ct. Vernant. 1988), ele e "forçado" a uma escolha. Comparada à situaçáo do homem trágico, a força da escolha de Cronos é ainda maior, pois, sendo ele um deus, náo está, a princlpio, sujelto a coerçbes divinas, além disso recebe da Terra náo uma imposiçăo, mas antes uma exortaçăo que, em álthma análise, nấo se dirige apenas a ele, mas lgualmente a seus irmấos. 
Nessa passagem, também é interessante o comportamento da Terra:

\begin{abstract}
"quantos salpicos respingaram sangülneos
a todos recebeu-os a Terra; com o girar do ano

gerou as Erinies duras, os grandes Gigantes

rútilos nas armas, com longas lanças nas mãos,

e ninfas chamadas Freixos sobre a Terra infinita."
\end{abstract}

(vv 183-87)

Mesmo tendo conspirado contra Urano, ela ainda recebe seu sangue, jorrado do golpe desferido por Cronos. Admitindo que a forma déksato ( $v$ 184) mais do que 'recebeu' pode significar 'recebeu favoravelmente, acolheu', a atitude da Terra poderia ser interpretada como uma espécie de submissão ou conformismo ao devir mf́tico, submissão esta resultante da consciência prévia de um destino já fixado. Nesse momento, esta consciência prévia pertence também a Urano e é explicitada nos versos:

"o pai como apelido de Titās apelidou-os:

o grande Céu vituperando filhos que gerou

dizia terem feito, na altiva estultícia

grã obra de que castigo teriam no porvir." (vv 207-10)

Ao devir mítico, o porvir narrado, não há como negar a importância das divindades emergentes da mutilaçāo do $\mathrm{Céu}$, especialmente as Erínies, relatadas mais adiante como co-responsáveis pelo castigo de Cronos, quando é destronado por Zeus:

"(...) e fosse punido pelas Erínies do pai

e filhos engolidos o grande Cronos de curvo pensar."

(vv 472-73)

Após descrever a derrota de Urano por Cronos, são registrados a descendência da Noite, a linhagem do Mar, os filhos de Tétis e Oceano - que, segundo uma outra tradiçăo, cuja referência é Homero (II. XIV, 302), seriam os pais de todos os deuses - e o hino à Hécate (cf. a divisão de Torrano 1981) para, em seguida, ser retomada a questão da transferência do poder, com a uniāo de Cronos e Réia:

"Réia submetida a Cronos pariu brilhantes filhos."

Esta união representa uma nova proposta de organização do mundo, ou ainda um outro estágio desta organização. Daf um novo poder emergirá, depois de outra batalha que elevará finalmente Zeus, pai dos deuseus e dos homens, ao poder. A chave deste novo momento é, como no anterior, um erro, um mau procedimento.

Sob certo aspecto, Cronos incorre na mesma hýbris do pai. O temor pela perda do poder leva-o a esta desmedida, ou seja, leva-o a depor contra o bom andamento do processo cósmi$c o$, a luta contra os designios superiores do próprio Zeus, em favor da conservação de uma ordem que já não pode mais ser. Assim, do mesmo modo que Urano, Cronos não permite virem à luz os filhos

\title{
"(..) para que outro dos magnificos uranidas
}

não tivesse entre os imortais a honra de rei."

(vv 461-62) 
Por este procedimento Cronos devia ser punido e outra vez é a figura feminina, no caso Réia, que intervém e solicita aos pais, Terra e Céu, que a auxiliem na empreitada, propiciando a emergência da nova geração, que trazia em si a instância definitiva do poder.

"(...) a Riéia agarrou-a longa aflição.
Mas quando Zeus, pai dos deuses e dos homens,
ela devia parir, suplicou então aos pais queridos,
aos seus, à Terra e ao Céu constelado,
comporem um ardil para que oculta parisse
o filho, e fosse punido pelas Erínies do pai
e filhos engolidos o grande Cronos de curvo pensar".

( $v$ v 467-73)

Réia, diferentemerite da Terra na mudança de poder anterior, não concebe nem governa os planos para o reequilibrio do cosmo, mas se submete aos procedimentos indicados pelos pais queridos, conforme o que ela havia solicitado. Esta intervenção, que não é a única, do Céu e da Terra como conselheiros e arquitetos de ardis, corresponde à certos aspectos presentes em alguns momentos do mito e que marcam decisivamente a cadeia das gerações e sucessões.

1) O mais superficial e evidente diz respeito à vingança e está ligado ao papel de Urano. A sua queda do poder e a mutilação sofrida são ambas obras de Cronos, que devem ser vingadas. A participação de Urano, então, tem um caráter, de certa forma, muito particular, Se por um lado cumpre os desígnios do universo, porque os conhece previamente, de outro lado, no cerne de seus compromissos, como mola propulsora, está também a sede de vingança. Novamente vale a citação dos versos:

"O pai com o apelido de Titãs apelidou-os:

o grande Céu vituperando filhos que gerou dizia terem feito, na altiva estultícia, grã obra de que castigo teriam no porvir."

(vv 207-10)

As próprias Erínies que, junto com os fithos engolidos, são agentes da punição. llustram claramente a situação, pois além de divindades identificadas pela tradição como vingadoras de crimes, simbolizam o ultraje sofrido por Urano, já que se criaram a partir de seu sangue respingado pelo golpe desferido por Cronos:

“(..) Mas nada inerte escapou da mão: quantos salpicos respingaram sanguiineos

a todos recebeu-os a Terra; com o girar do ano

gerou as Erinies duras (...)" (vv 182-85)

"(...) se fosse punido pelas Erínies do pai

e filhos engolidos o grande Cronos de curvo pensar."

(vv 472-73)

2) Um outro aspecto diz respeito à relação da Terra, na tradição grega antiga, com as profecias e oráculos que predizem e revelam o devir. Gaia age, então, segundo seu prévio co- 
nhecimento e trabalha para o cumprimento dos desígnios cósmicos. Um indício desta função profética é dado pelo próprio texto:

"Zeus cravou-a (a pedra) sobre a terra de amplas vias em Delfos divino, nos vales ao pé do Parnaso, signo ao povir e espanto aos pereciveis mortais."

(vv 498-500)

Se se pode aceitar a fragilidade, no mito, dos limites entre a terra potestade e a terra física, 0 ato de Zeus legitima a sabedoria de Gaia, através da pedra que funda, no seio do chão, o principal oráculo grego, mais tarde entregue aos cuidados de Apolo e de suas pitonisas, do qual, conta-se, até Sócrates serviu-se (Cf. Platão, Defesa de Sócrates).

$\mathrm{Na}$ tradição, principalmente nos mitos homéricos, a Terra também representa, tanto como entidade fisica como divina, uma confluência de domínios por onde passam e onde atuam outras instâncias de poderes divinos, bem como a instância humana, ou seja, se deusa, é transformada em uma espécie de superposição ou amálgama de outras forças divinas (ela é matriz), e, se entidade física, converte-se em palco de inúmeras façanhas e ações dos deuses e dos pereciveis mortais. Como observa J. P. Vernant (1984:75): "O mundo de Homero ordenava-se por uma distribuição dos dominios e funçōes entre grandes deuses: a Zeus cabe a luz brilhante do céu (aithér); e a Hades, a sombra brumosa (aér); a Posidão, o elemento líqüido; a todos os três, em comum, Gaia, a Terra, onde vivem com os homens todas as criaturas mortais que resultam da mistura." Verdade é que, em Homero, os deuses não se comportam como em Hesiodo, justamente pela diferença do tipo de relato mítico. Se, no primeiro, o mundo divino cruza com o humano, no segundo o homem está, a princípio, radicalmente excluido. Contudo o perfil mitológico que se forma a partir das duas versōes garante à Terra um estatuto que sustenta e confirma as suas faculdades vaticinatórias, pois não é diffcil conceber que uma entidade que conjuga tamanhas e distintas potências venha a ter o segredo de seus resultados.

3) Outro dado importante é a personificação, pelo Céu e pela Terra, de uma espécie de triângulo formado por três papéis correlatos: pais, anciāos e conselheiros. O papel do velho, na cultura grega, sempre aparece muito bem definido e o que encontramos, a esse respeito, no mito cosmogônico de Hesiodo, coaduna-se perfeitamente com os relatos da épica homérica, e da tragédia.

Pelo menos em um primeiro momento, em Homero sobretudo, a longevidade e a velhice não eram bens ideais que o espírito heróico dos gregos se permitia propriamente perseguir a todo custo. $O$ jovem guerreiro realizava a sua bravura no desafio dos combates, aproximando-se deliberadamente cada vez mais de um desfecho fatal e nada podia detê-lo; e se acaso os deuses o presenteassem com uma bela morte, no afã de uma batalha, então era a confirmação de sua areté. Mas se sobrevivesse, sem nunca ter temido e evitado a morte nem nenhum perigo chegando finalmente à velhice, sua excelência passava a uma outra esfera. $\mathrm{Na}$ verdade, tudo era uma questão de oportunidade, de adequação: um velho não sustenta mais a espada e nem deverá tentá-lo. Tirteu diria que nada é mais hediondo do que um velho, com as vergonhas ensangüentadas nas próprias mãos, caido morto no campo de batalha (Cf. Licurgo. Leocr. 107). Esta é uma cena inoportuna, inadequada. Por outro lado, ao anciāo cabe a sabedoria que a experiência dos anos vividos concede e sua palavra, proferida na ágora, diante dos mais jovens, carrega em si uma força enorme, tão grande quanto a força dos golpes que outrora podia desferir contra os inimigos. Assim, excluido da peleja, no sentido físico, ainda podia interferir nos seus destinos, através de pertinentes conselhos, como constantemente podemos observar na lliada: um homem velho (Nestor, por exemplo) orientando os jovens heróis, chefes de guerreiros, para o melhor procedimento no comando de suas tropas.

Processo semelhante se dá, em Hesiodo, com Gaia e Urano. Se do poder direto ou de sua execução estão, a princípio, excluídos, ainda atuam nos destinos do universo porque conhecem os seus desígnios, fazendo-se presentes com prognósticos acertados nos momentos 
mais importantes do mito. A Terra é quem indica a Cronos o modo pelo qual derrotaria Urano; na mudança seguinte, também a Terra, agora com a participação do Urano, é que compōe o ardil e providencia "repetidas instigações" ( $v$ 494) para que Zeus substitua Cronos; "por conseIhos da Terra e do Céu constelado" ( $v .891$ ), Zeus é auxiliado na sucessão dos procedimentos que empreende para conservar o poder.

A comparação entre a função conselheira dos deuses, na Teogonia, e a do herói homérico carece de uma consideração importante. A extensão desta análise deve estar resguardada pelas diferenças de natureza que envolvem deuses e homens. Com referências ainda à lliada (III. 150 ss), escreve W Schadewaldt (1981:09): "O poeta vê a força e a debilidade da idade maravilhosamente unidas na imagem da cigarra, do animal seco e contraldo com a voz clara e ressonante". O herói, envelhecido e sábio, de Homero, enquanto humano, não pode evitar a sombra que a morte paulatinamente verte sobre ele, ameaçando apagar a sua gloria que, ao contrário daquela do jovem guerreiro, só encontra sentido em vida, através de suas palavras aladas. A morte para ele não é mais tão bela, porque não traz mais, como nas batalhas, a possibilidade de imortalizaçāo e celebridade com o canto dos aedos.

Esta limitação, se pesa sobre os pereciveis mortais, ressalta a potência dos conselhos do Céu e da Terra, pois, isentos da mortalidade, concentram ainda mais o conhecimento e a sabedoria sobre as coisas do universo divino.

Retomando o fio de sucessão, é importante observar que o modo de transferência do poder de Cronos para Zeus se opōe radicalmente ao modo como se realizara de Urano para Cronos. Enquanto neste caso o ponto culminante é um ato de violência física, a mutilaçāo, naquele existe apenas o emprego da artimanha, de um jogo astucioso que envolve Terra, Céu, Réia e Zeus, de um lado, e Cronos de outro. Percebemos, com isto, uma maior aproximação do mito de um referencial ligado ao mundo humano, cujas conquistas partem não só da força bruta, que irrompe nas batalhas, mas também da habilidade política, talvez ainda mais eficiente justamente porque pode tornar mais eficaz a outra faculdade.

Essa aproximação maior de um modelo humano é Zeus quem melhor a representa. É o primeiro e o único que assume, em Heslodo, os contornos do verdadeiro rei. Primeiro, porque sob seu dominio o universo assume uma complexidade até então ausente; por outro lado, e principalmente, porque a ele cabe realizar a partilha dos domínios universais, verdadeiro Télos do mito cujo objetivo, conforme a declaração inicial das musas, é revelar

"como dividiram a opulência e repartiram as honras

e como no começo tiveram o rugoso Olimpo." (v'v 112-13)

Para isto Zeus congrega em si as mais fortes potências, tanto no plano físico quanto no intelectual. Zeus não é mais, como Cronos, ankylométes, aparece como Zeus metíeta, pois possui uma astúcia não angulosa, ou distorcida, mas perfeita, capaz do exato discernir.

Zeus empreende, então, uma série de batalhas não apenas bélicas que vão definindo a organização final do mundo. Vernant (1984:78) escreve: "A vitória de Zeus, em cada vez, é uma criação do mundo". E a força da sua realeza se dá pela amplitude destas vitórias frente à amplitude e à diversidade das situaçōes. Assim, no começo, para a derrota de Cronos, conta com a ajuda do Céu constelado e da Terra, bem como da mãe Réia; depois, sem ajuda externa, valendo-se apenas de suas virtudes, vence Prometeu e cumpre a partilha entre deuses e homens; em seguida, no exercicio de um poder verdadeiramente militar de comando, de novo com o auxnio da Terra, lidera os deuses olímpicos na magnífica luta contra os Titãs, a qual vence e estabelece, para todo o sempre, a diferença entre os deuses derrotados e os deuses doadores-de-bens; por último, derrota Tifeu, monstro gerado pela Terra e Tártaro. Curiosamente (talvez pela interferência do Tártaro), a Terra, que sempre colaborou na conservação da ordem de Zeus, neste episódio gera um ser que vive exatamente ameaçar esta ordem, como se para confirmar a definitiva supremacia do pai dos deuses e dos homens.

Em seguida, "quando os imortais completaram a fadiga" (v 881), Zeus deve se precaver, como tentaram Urano e Cronos, contra a possibilidade de ser destronado por um sucessor, re- 
cebendo ainda mais uma vez a colaboração da Terra e do Céu para o sucesso de sua ação. Diferente dos antecessores, Zeus, antes de tudo, desposa e logo devora a própria Astúcia, ou seja, possui a deusa em dois sentidos, assumindo para si as suas virtudes:

\section{"Zeus rei dos deuses primeiro desposou Astúcia mais sábia que os deuses e os homens mortais. \\ Mas quando ia parir a deusa de olhos glaucos \\ Atena, ele enganou suas entranhas com ardil, com palavras sedutoras, e engoliu-a ventre abaixo, por conselhos da Terra e do Céu constelado. \\ Estes tho indicaram para que a honra de rei \\ não tivesse em vez de Zeus outro dos deuses perenes". (vv 886-93)}

Cada procedimento de Zeus, ou melhor, a sucessão destes procedimentos tem, na verdade, um sentido único: afastar e confirmar o afastamento, em cada passo dado, da ameaça de uma nova imersão do mundo na desordem. Isso significa excluir, para sempre, ainda que se tenha que destruir uma ordem presente, o Caos e as trevas da superfície do Universo.

\section{RÉSUMÉ}

La Théogonie d'Hésiode est un récit mythique qui décrit le mouvement de l'univers, depuis le principe jusqu'à l'ordre finale, hiérarchisée d'après des puissances divines, et comme ce mouvement se révèle aux hommes à travers la force presentificatrice des Muses. Ce travail cherche, exactement, à délinéer, sous le point de vue du pouvoir, les générations et les successions dans le mythe, en partant du Ciel, bien comme interpréter ce qui réprésente chaque instance du pouvoir, la façon comme elle s'instaure et se comporte, étant à service de l'ordre dans le processus d'évolution du monde.

\footnotetext{
* Pesquisa patrocinada pelo CNPq.
}

\section{REFERÊNCIAS BIBLIOGRÁFICAS}

BONNAFIÉ, A. Eros et Eris: mariages divins et mythe de succession chez Hesiode. Lyon: Presses Universitaires de Lyon, 1985.

DETIENNE, M., VERNANT, J. P. Las artimanas de la inteligencia. Trad. Antônio Pinero. Madrid: Taurus, 1988.

-. Mito e tragédia na Grécia antiga. Trad. Ana Lia A. de Almeida Prado, Filomena Y. H. Garcia e M. da Conceição M. Cavalcante. São Paulo: Brasiliense, 1988.

HESIODE. Theogonie-Les travaux et les lours-Le bouclier. Texte établi et traduit par Paul Mazon. Paris: Le Belles Lettres, 1983.

HESíODO. Teogonia. Trad. do original grego e coment. por Ana Lúcia S. Cerqueira e Maria Therezinha A. Lyra. Rio de Janeiro: UFF, 1979.

HESIODO. Teogonia a origem dos deuses. Estudo e tradução por Jaa Torrano. São Paulo: Roswitha Kempl.

RAMNOUX, C. La nuit et les enfantes de la nuit dans tradition grecgue. Paris: Flamarion, 1959.

RUDHARDT, J. Le role d'Eros et d'Aphrodite dans les cosmogonies gregues. Paris: PUF. 1986.

SCHADEWALDT, W. La actualidad de la antigua Grecia. Trad. Miguel López Calderón. Barcelona: Editorial Alfa, 1981.

TORRANO, J. O sentido de Zeus. Săo Paulo: Roswaitha Kempf, 1988.

VERNANT, J. P. As origens do pensamento grego. Trad. Isis Borges B. da Fonseca. São Paulo: DIFEL, 1984. 